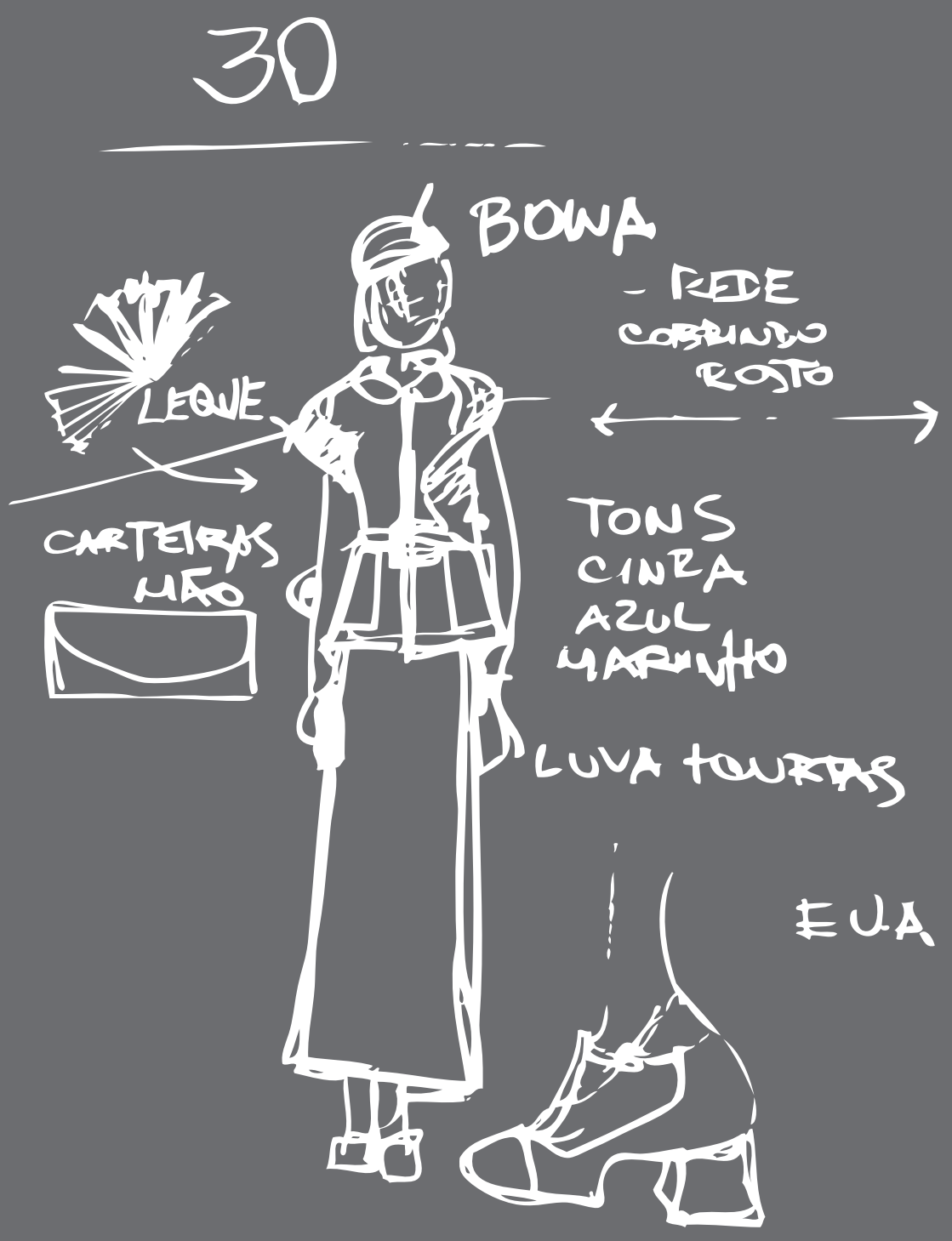



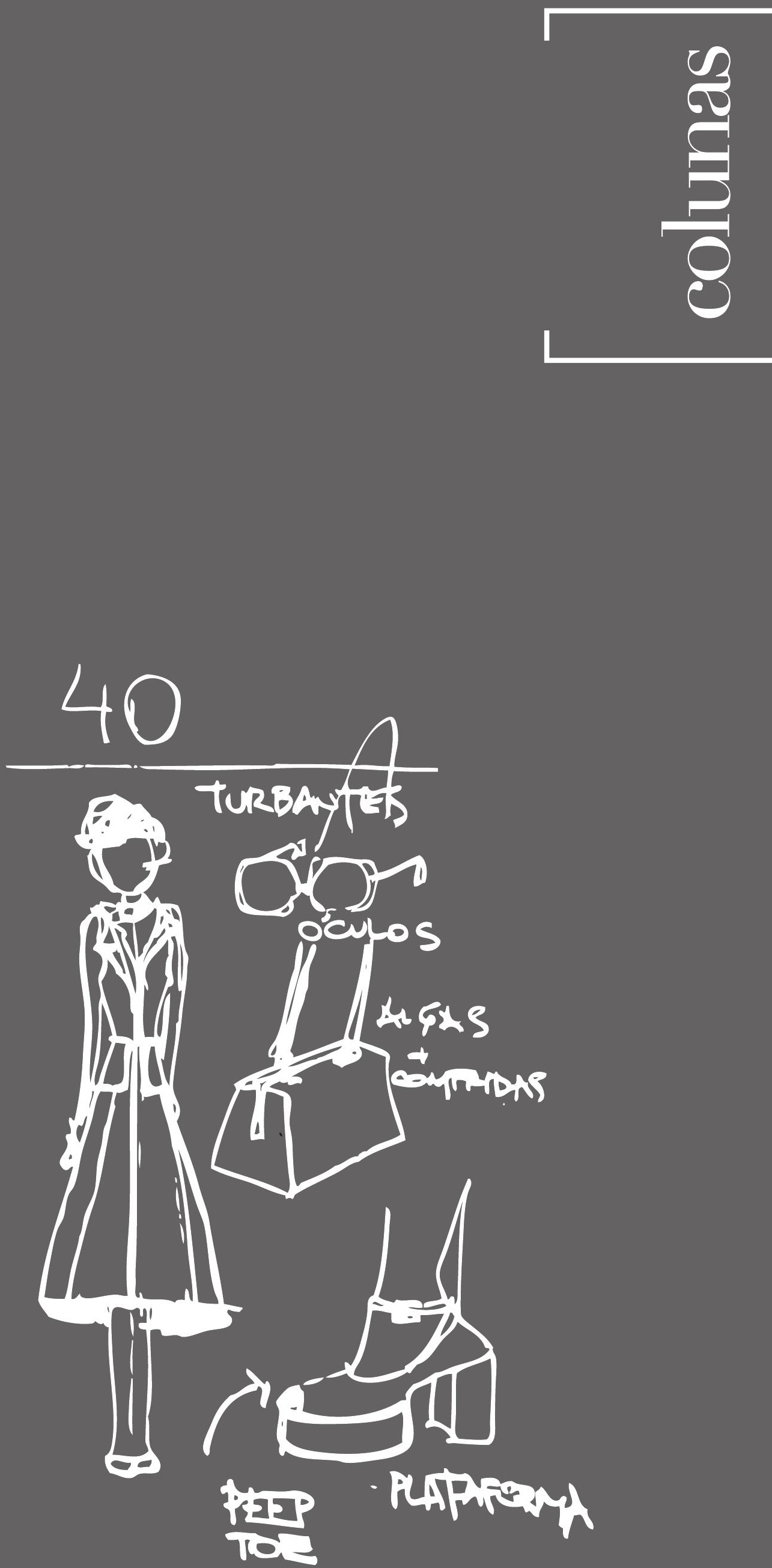


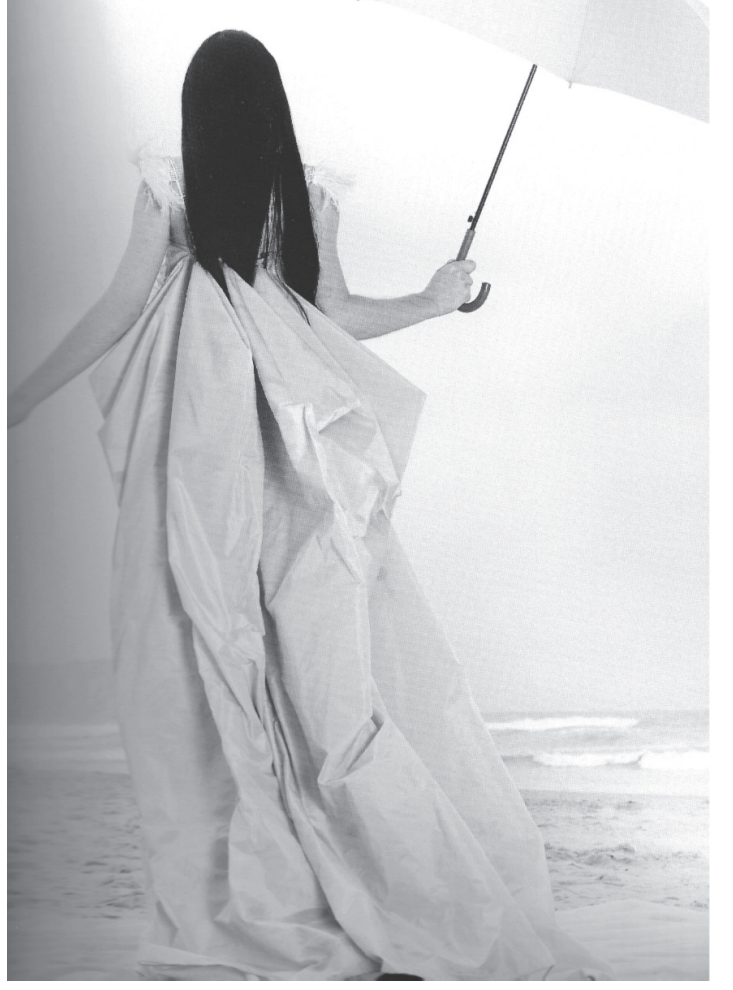

[ MINISTÉRIO DAS RELAÇÕES EXTERIORES ]

www.itamaraty.gov.br

\section{Considerações sobre moda e diplomacia}

O Brasil está na moda. 0 crescimento econômico e as mudanças sociais pelas quais o país vem passando desde a redemocratização acabaram por assegurar ao Brasil um espaço de inédita importância no conjunto das nações. Rótulos como "potência regional" ou "país emergente" já não bastam para definir essa enorme democracia multicultural e multiétnica, pacífica, que caminha para ser a quinta economia do mundo, ao mesmo tempo em que reduz a pobreza e as desigualdades sociais.

A imensa demanda por conhecer e entender o Brasil traduz-se em um interesse crescente pela arte e pela realidade brasileiras; interesse este que vem sendo percebido com muita clareza pelo Departamento Cultural do Itamaraty.

Para desempenhar suas funções de difundir a cultura e divulgar o Brasil no exterior, o Departamento Cultural do Itamaraty tem empregado os mais diversos instrumentos, como o apoio a mostras de cinema, exposições de arte e fotografia, apresentações de música, teatro e dança. Merece destaque, porém, uma das mais eficazes ferramentas de divulgação no exterior que é a elaboração de publicações sobre temas em que o país possui excelência comprovada, como é o caso da revista Textos do Brasil.

Voltada para o público estrangeiro, Textos do Brasil enfoca, a cada ano, dois temas relevantes da cultura brasileira, como música erudita, música popular brasileira, gastronomia, capoeira, festas populares, teatro e futebol. A publicação é traduzida em pelo menos quatro idiomas e distribuída gratuitamente para toda a rede de embaixadas, consulados e centros de cultura brasileiros, bem como a interlocutores dos setores político, cultural, empresarial e acadêmico. Cada publicação reúne imagens, entrevistas e ensaios sobre diferentes aspectos do tema abordado, visando apresentar ao público estrangeiro uma visão exaustiva, que permita o debate e a reflexão sobre a matéria.

0 assunto escolhido para a última edição de Textos do Brasil, lançada em 2011, é a moda brasileira. Superando os preconceitos de quem a considera tema fútil, a moda, cada vez mais, tem sido aceita como manifestação artística e cultural, e, no caso do Brasil, evidencia uma evolução notável nas últimas duas décadas, como se observa pelo número crescente de designers de moda dotados de grande capacidade criativa. Além disso, trata-se de uma indústria que movimenta um nada desprezivel volume de recursos e gera milhares de empregos diretos e indiretos, com base na produção de bens de grande valor agregado. A difusão da moda brasileira no exterior, portanto, atinge uma intersecção entre o trabalho de divulgação cultural e a promoção comercial propriamente dita.

Para corroborar a oportunidade de investir na difusão da moda brasileira no exterior, o Relatório de Economia Criativa, recentemente elaborado pelo Programa das Nações 
Unidas para o Desenvolvimento (PNUD), em conjunto com a Conferência das Nações Unidas para Comércio e Desenvolvimento (UNCTAD), aponta que

apostar na indústria criativa - setor que engloba serviços e produtos culturais diversos (incluindo comunicação, arquitetura e artesanato) pode ajudar os países em desenvolvimento a alcançar ao menos seis metas dos Objetivos de Desenvolvimento do Milênio'.

A diplomacia atual, cada vez mais focada em substância e resultados, encontra-se muito distante da imagem, gravada no imaginário popular, de uma atividade de representação desempenhada entre coquetéis, jantares e punhos de renda. No entanto, conceitos como moda, estilo e aparência não são estranhos à atividade diplomática. Protocolo e cerimonial são formalidades inerentes ao desempenho da diplomacia, atividade historicamente caracterizada por um dress code (código do bem-vestir) muito específico. Se a atividade diplomática não se notabiliza por seguir a moda em seus últimos ditames, a elegância clássica e discreta - no trajar e no relacionar-se - é um dos instrumentos de trabalho do diplomata.

O Barão do Rio Branco, patrono do Ministério das Relações Exteriores e inspiração constante para todos os diplomatas, era conhecido por seu senso de estilo. Como observa Álvaro Lins, um dos principais biógrafos do barão,

Como o Visconde [seu pai], ele se destacava pela elegância; e porque se vestia pela moda, oferecia o aspecto de um dândi, com a tendência para os gestos aristocráticos. 0 seu dandismo era uma nova forma de aristocracia, a afirmação aristocrática pelo exterior. (...) Pertencia Juca Paranhos à classe dos elegantes, que um cronista da época distinguia do seguinte modo: "ser indivíduo de bom tom é possuir por ano seis sobrecasacas, calças e coletes na mesma proporção, conforme os caprichos da moda"?

Talvez como mais um dos grandes legados deixados pelo Barão de Rio Branco, permanece até hoje no Itamaraty um grande apreço pela elegância, reconhecido pelo estudioso norte-americano Alan J. Flusser ${ }^{3}$, responsável pelo impecável guarda-roupa de Michael Douglas no filme Wall Street: poder e cobiça (direção de Oliver Stone, 1987): "Nos anos trinta, nenhum grupo de cavalheiros era conhecido por emanar maior elegância coletiva que o corpo diplomático brasileiro"4.

Pode-se dizer, portanto, que a edição de uma publicação sobre moda está dentro da melhor tradição diplomática brasileira de promover nossa excelência cultural.

Se a moda e o estilo não são estranhos à diplomacia, menos ainda o são a sua atividade irmã, a política. Desde tempos imemoriais, reis e rainhas sabem que se paramentar e se apresentar ao público da maneira correta faz parte da razão de Estado. Em tempos de rápida circulação - e consumo - de informações e fotografias, o uso da imagem pública para transmitir importantes mensagens políticas tem adquirido cada vez mais relevância.

0 personagem mais emblemático desse casamento entre estilo e política foi, possivelmente, Jacqueline Kennedy. A graça, a elegância e o frescor da primeira-dama ajudaram a enfatizar as mensagens de mudança, esperança e otimismo que elegeram John Kennedy e caracterizaram seu breve período na Presidência. Nas palavras do editor europeu da revista Vogue, Hamish Bowles:

A imagem de Jacqueline Kennedy como Primeira-Dama era tão cuidadosamente construída quanto o cenário que ela criou para a Presidência de seu marido, em sua escrupulosa restauração da Casa Branca. Seu gosto pessoal graciosamente serviu de ponte entre a América dos anos 1950 e a Nova Fronteira ("New Frontier") de John F. Kennedy. Ela era ao mesmo tempo um paradigma de classe à moda antiga, que compartilhava com o marido um gosto por História e uma apreciação das normas cerimoniais, e um ícone pop relutante, que, como John F. Kennedy, tinha um intuitivo entendimento do poder da imagem em uma era em que a televisão estava começando a se popularizar. ${ }^{5}$

Ao assumir a coroa da Inglaterra, Elizabeth II elegeu os estilistas Norman Hartnell (1901-1979), que fez o vestido de noiva e o vestido de lua de mel, e Hardy Amies 
(1909-2003), para estabelecer uma imagem adequada à sua posição - silhuetas foram definidas; as cores... claras, brilhantes e puras; os chapéus não deveriam cobrir a face que a multidão ansiava por ver. ${ }^{6}$ Posteriormente, a imagem moderna e sempre "na moda" da princesa Diana fez muito para renovar o interesse - e a afetividade em torno da vetusta monarquia britânica. Esse papel agora cabe à princesa Catherine Middleton, também muito identificada com o universo da moda, cujo vestido de noiva foi tratado como segredo de Estado.

Mais recentemente temos exemplos do que a imprensa internacional passou a classificar como fashion diplomacy. 0 primeiro deles diz respeito à primeira-dama da França, Carla Bruni-Sarkozy, que conferiu notoriedade à visita oficial de seu marido à Inglaterra ao usar, com a desenvoltura típica de uma ex-top model, um figurino inteiramente criado pelo estilista inglês John Galliano, à época responsável pela tradicional Maison Dior. A imagem da primeira-dama de vestido e chapéu cinza, cumprimentando a Rainha Elizabeth com graciosa reverência, circulou pela mídia e chamou grande atenção para a visita do casal francês ${ }^{7}$.

Outro exemplo é Michelle Obama, primeira-dama dos Estados Unidos, reconhecida por sua elegância e acertados figurinos. Em visita presidencial à Índia, Michelle desceu do avião com um vestido cinza com botões de pérolas, claramente inspirado na tradicional túnica kurti indiana - a indumentária foi suficiente para que os jornais locais falassem em um aceno de boa vontade para com o país anfitrião ${ }^{8}$. As escolhas fashion de Michelle são importantes não apenas para fins diplomáticos, mas têm grande peso no mercado de moda norte-americano. Recente estudo da Harvard Business Review revelou que Michelle Obama pode gerar até 14 milhões de dólares em receita para uma marca cada vez que usa em público um item de vestuário.

No mundo árabe, a Sheika Mozah, do Qatar, adota um figurino que harmoniza Oriente e Ocidente. Sempre de cabelos escondidos por turbantes, a segunda esposa do Emir adapta, com grande sucesso, a moda internacional às exigências de sua religião. A indumentária da Sheika, que é relações-públicas da Qatar Foundation para Educação, Ciência e Desenvolvimento Social, ajuda a compor a imagem de um Qatar moderno e ocidentalizado, mas fiel às suas origens. ${ }^{10} 0$ destaque conferido à Sheika na cerimônia da Fifa em que o Qatar foi escolhido para sediar a Copa do Mundo de 2022 - vitória inédita para um país do Oriente Médio - foi interpretado como "um recado ao mundo, de forma sutil, de que o Catar, embora seja um país muçulmano com normas rígidas, respeita suas mulheres"11.

Os exemplos citados evidenciam, com bastante clareza, a crescente importância da moda como manifestação cultural. É com base nessa percepção que o Departamento Cultural do Itamaraty decidiu somar esforços no trabalho de divulgação da moda brasileira no exterior.

\section{NOTAS}

[1] Disponivel em: <http://www.pnud.org.br/educacao/reportagens/index.php?id01=3643\&lay=ecu>. Acesso em: 12/04/2011.

[2] LINS, Álvaro. Rio Branco. São Paulo: Alfa-Ômega, 1996, p. 88-89.

${ }^{[3]}$ Nota das editoras: Para saber mais, veja Style and the man: how and wuere to buy fine men's clothes e Dressing the man: mastering the art of permanent fashion, ambos da editora Harper (EUA).

${ }^{[4]}$ No original: "Back in the thirties, no group of swells was alleged to exude more collective swank than the Brazilian diplomatic corps". Tradução livre da autora. FLUSSER, Alan. Dressing the man: mastering the art of permanent fashion. Harper Collins, 2002, p. 124

${ }^{[5]}$ Tradução livre da autora. BOWLES, Hamish. Defining style: Jacqueline Kennedy's White House years. In: Jacqueline Kennedy: the White House years - selections from the John F. Kennedy Library and Museum. Nova York: Bullfinch, 2001, p. 87.

${ }^{[6]}$ Tradução livre da autora. BOWLES, Hamish. Defining style: Jacqueline Kennedy's White House years. In: Jacqueline Kennedy: the White House years - selections from the John F. Kennedy Library and Museum. Nova York: Bullfinch, 2001, p. 152.

${ }^{[7]}$ Disponivel em: <http://www.telegraph.co.uk/news/worldnews/1583145/Carla-Bruni-charms-UKwith-fashion-diplomacy.html>. Acesso em: 12 abril 2011.

${ }^{[8]}$ Disponivel em: <http://articles.economictimes.indiatimes.com/2010-11-07/news/27568390_1_ fashion-dress-designer>. Acesso em: 20 abril 2011.

[9] Disponivel em: <http://atlantapost.com/2010/10/27/the-mrs-obama-effect-on-retail-earnings>. Acesso em: 20 abril 2011.

${ }^{[10]}$ Disponivel em: <http://veja.abril.com.br/260510/quando-isla-rima-louboutin-p-142.shtml>. Acesso em: 20 abril 2011.

[11] Disponivel em: <http://veja.abril.com.br/blog/gps/esporte/sheika-mozah-do-catar-na-vitoria-parasediar-a-copa-ela-brilhou>. Acesso em: 20 abril 2011. 